\title{
Initial Electrochemical Activity of Magnesium Alloy AZ31 Surface Exposed to Simulated Body Fluid by Scanning Electrochemical Microscopy
}

\author{
Emmanuel Mena Morcillo ${ }^{1}$, Lucien Veleva ${ }^{1 *}$ and David 0 Wipf $^{2}$ \\ ${ }^{1}$ Applied Physics Department, Center for Investigation and Advanced Study, (CINVESTAV-IPN), Merida, Yucatan, Mexico \\ ${ }^{2}$ Department of Chemistry Mississippi State University, Mississippi State, Mississippi, USA
}

Received: 制 December 22, 2018; Published: 制January 17, 2019

*Corresponding author: Lucien Veleva, Applied Physics Department, Center for Investigation and Advanced Study (CINVESTAV-IPN, Merida), Merida, Mexico

\begin{abstract}
This study applies scanning electrochemical microscopy (SECM) in feedback mode to monitor the initial activity of AZ31 magnesium alloy surface, exposed to simulated body fluid (SBF). The alloy surface suffers a degradation process since the very first moments of immersion, considered as intense uniform activity and later a localized attack was detected. The additional information provided by SEM-EDS helped to characterize the composition of sites of interest observed on the AZ31 surface. The corrosion layer contains O, C, P and Ca coming from the SBF solution, as well as the basic elements of the alloy $\mathrm{Mg}, \mathrm{Al}, \mathrm{Zn}$ and $\mathrm{Mn}$. The results allowed concluding that the locally formed pits nucleated around Al-Mn intermetallic particles in contact with the Mg alloy matrix, as a consequence of chloride ions attack.
\end{abstract}

Keywords: Magnesium Alloy; AZ31; SBF; Corrosion Degradation; SEM-EDS; SECM

Abbreviations: SECM: Scanning Electrochemical Microscopy; SBF: Simulated Body Fluid; SEM: Scanning Electron Microscope

\section{Introduction}

Over the last years, magnesium alloys have been demonstrated to be the most promising biodegradable and resorbable materials for medical implants applications. They present physical and mechanical properties close to those of natural bone, thus avoiding the effects of stress shielding [1-6]. In addition, the released Mgions during the implant degradation bind strongly to phosphates, which are part of physiological human solution, thus promoting bone cell attachment and tissue growth on the implants [711]. Many previous studies have been performed on Mg alloys, employing conventional electrochemical techniques, which only reflect the average electrochemical behavior of the entire surface. Therefore, it is necessary to assess the activity of these materials through other methods, in order to gain more information about local changes occurring at alloys surface [12,13]. Local probe techniques are a suitable option for characterizing these materials in physiological environments. Among them, the scanning electrochemical microscopy (SECM) is an advantageous tool, which allows detection of electrochemical processes in situ with high spatial and electrochemical resolution [14].
SECM in Feedback Mode: The feedback mode of SECM is the most widely used one. In this mode, a current flow through a microelectrode situated close to a substrate and immersed in an electrolytic solution having a redox mediator. Typically, the micro-disk electrode is set at a potential that allows to attain a steady state diffusion-controlled current $i T, \infty$, resulting from the electrochemical reaction of the mediator redox pair $(0+$ ne- $\leftrightarrow R)$, where iT, $\infty$ becomes a function of the concentration of reactant species and its diffusion coefficient, as shown by the following equation:

$$
i T, \infty=4 n F D c a
$$

where, $\mathrm{n}$ is the number of electrons transferred in the redox reaction, F - the Faraday constant, D - the diffusion coefficient, c - the concentration, and a is the microelectrode radius. Figure 1 illustrates the principle of operation of the feedback mode of SECM. The capabilities of SECM in this operation mode allow to monitor different systems in situ. However, only a few studies on Mg alloys have been conducted with SECM [15-24], of which not all focus on 
biomedical applications. The goal of this study is to detect through SECM the initial stages of electrochemical activity on AZ31 Mg alloy surface during its exposure to buffered simulated body fluid (SBF).

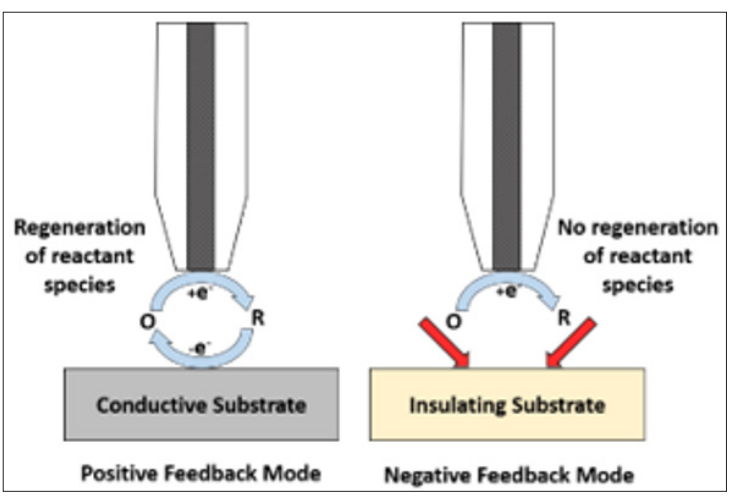

Figure 1: Schematic representation of SECM feedback mode used in this work.

\section{Experimental}

Samples and Solutions Preparation: The chemical composition of AZ31 magnesium alloy (provided by Magnesium Elektron Ltd., Swinton, England) is listed in Table 1. It was fabricated in wrought condition, in the form of sheets of $2 \mathrm{~mm}$ thick. The alloy was cut into strips and then embedded in epoxy resin, exposing an area of $120 \mu \mathrm{m}$ x $100 \mu \mathrm{m}$ approximately. Before each experiment, samples were abraded with 400, 800 and 1200 grit SiC papers using ethanol as lubricant, and then polished with $0.3 \mu \mathrm{m}$ alumina ethanolic suspension. After that, samples were sonicated in ethanol and dried in air. Finally, samples were mounted in a Teflon container, facing upwards. The simulated body fluid (SBF) was prepared using analytical grade reagents (Table 2), ultrapure deionized water (18.2 $\mathrm{M} \Omega \mathrm{cm}$ ), and following a detailed procedure described in reference [25]. Ferrocenemethanol (FeMeOH) supplied by Across Organics (New Jersey, USA) was used as the redox mediator with a $5 \mathrm{mM}$ concentration for Feedback mode of SECM test.

Table 1: Chemical composition of AZ31 Mg alloy (wt.\%).

\begin{tabular}{|c|c|c|c|c|c|c|c|c|c|}
\hline Alloy & Al & Zn & Mn & Si & Cu & Fe & Ni & Ca & Others \\
\hline AZ31 & 3.1 & 0.73 & 0.25 & 0.02 & $<0.001$ & 0.005 & $<0.001$ & $<0.01$ & $<0.30$ \\
\hline
\end{tabular}

Table 2: Reagents and their amounts for preparing $1000 \mathrm{~mL}$ of SBF.

\begin{tabular}{|c|c|c|c|}
\hline Reagent & Amount (g) & Reagent & Amount (g) \\
\hline $\mathrm{NaCl}$ & 5.403 & MgCl2·6H20 & 0.311 \\
\hline $\mathrm{NaHCO}_{3}$ & 0.740 & HEPES & 11.928 \\
\hline $\mathrm{Na}_{2} \mathrm{CO}_{3}$ & 2.046 & $\mathrm{CaCl} 2$ & 0.293 \\
\hline $\mathrm{KCl}$ & 0.225 & $\mathrm{Na} 2 \mathrm{SO}$ & 0.072 \\
\hline $\mathrm{K}_{2} \mathrm{HPO}_{4} \cdot 3 \mathrm{H}_{2} \mathrm{O}$ & 0.230 & $\mathrm{NaOH}(1.0 \mathrm{M})$ & $\approx 0.8 \mathrm{~mL}$ \\
\hline
\end{tabular}

\section{Instrumentation:}

Scanning electrochemical microscopy (SECM) experiments were performed with an instrument built as described in references [14, 26]. Figure 2 presents an overview of the SECM setup. Optical and SEM images of the alloy surface were acquired before immersion in SBF and at the end of experiments with a BH2 model optical microscope (Olympus Co., Shinjuku, Tokyo, Japan) and a scanning electron microscope (SEM-EDS, Philips XL-30, Amsterdam, The Netherlands).

\section{SECM experiments:}

The microelectrode employed in this study was fabricated using a $7 \mu \mathrm{m}$ diameter carbon fiber (Amoco Performance Products
Inc., Chicago, IL, USA) following a procedure described in literature [27]. Figure 3 shows an optical image of the microelectrode. The electrochemical cell for SECM measurements was completed with a $0.7 \mathrm{~mm}$ Pt wire (Alfa Aesar, Ward Hill, MA, USA) and an Ag/AgCl/ $\mathrm{KCl}$ reference electrode prepared using a $0.6 \mathrm{~mm}$ diameter Ag wire (Goodfellow Cambridge Ltd, Huntingdon, England) [28]. Positioning of the microelectrode was done with the tip set at $+0.50 \mathrm{~V}$ in order to ensure complete diffusion-limited oxidation of ferrocene to ferrocenium. Once positioned, the tip was fixed at a constant height of $8-10 \mu \mathrm{m}$ from the sample surface, and then the X-Y plane was scanned at the convenient potential for the experiment. Thus, 3D maps were obtained, where $\mathrm{Z}$ coordinate indicates the tip current response.

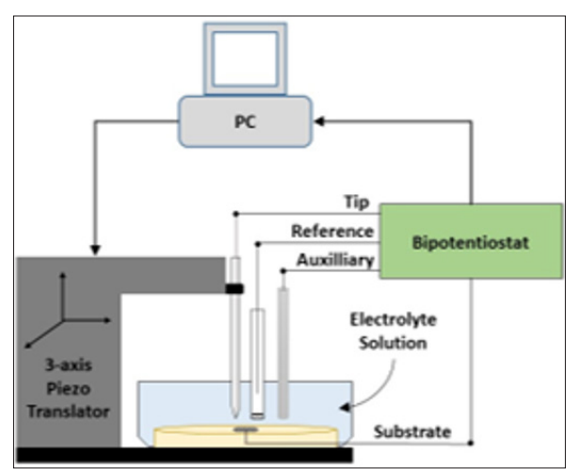

Figure 2: Schematic representation of SECM feedback mode used in this work.

Cite this article: Emmanuel Mena M, Lucien V, David O W. Initial Electrochemical Activity of Magnesium Alloy AZ31 Surface Exposed to Simulated Body Fluid by Scanning Electrochemical Microscopy. Biomed J Sci \& Tech Res 13(2)-2019. BJSTR. MS.ID.002374. DOI: 10.26717/ 


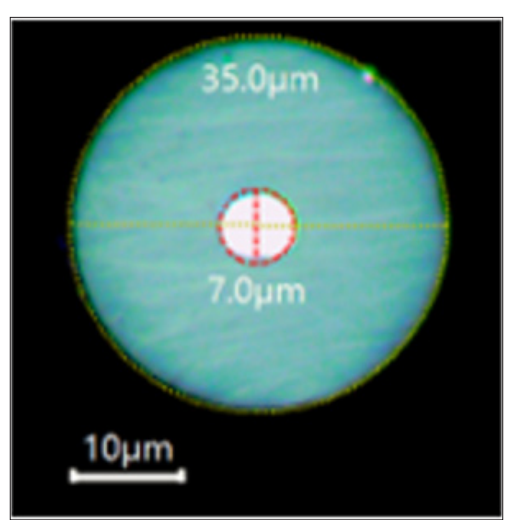

Figure 3: Optical Images of the carbon fiber microelectrode (RG $\approx 5)$.

\section{Results and Discussion}

Figure 4 shows the SECM maps acquired at 10 minutes, 1 hour, and 2 hours. The experiments were done with the AZ31 substrate exposed to SBF with $5.0 \mathrm{mM} \mathrm{FCMeOH}$ added as mediator. The substrate was left at its OCP and the tip performed scans at a constant height of $7 \mu \mathrm{m}$, with a rate of $20 \mu \mathrm{m} / \mathrm{s}$ and a gain of 1 $\mathrm{nA} / \mathrm{V}$. An approximate scan time of 20 minutes was required for each map. At 10 minutes of exposure (Figure 4A), the whole surface presented a relative constant value of current, reflecting a uniform electrochemical activity over the substrate. The measured current activity (iT) increased after 1 hour of exposure (Figure 4B) and the uniform behavior on the surface continued. An increase in the electron transfer rate (current value) could be related to changes in the alloy surface, related to higher corrosion rate even in the presence of corrosion layer. After 2 hours of exposure (Figure 4C), the surface presented a noticeable localized corrosion in some most active sites, where the current values increased. The above is usually attributed to nucleation of pits, as a consequence of more pronounced chloride ions attack. The provided optical images reveal an evidence of the changes that AZ31 substrate suffered at the end of the exposure to SBF.

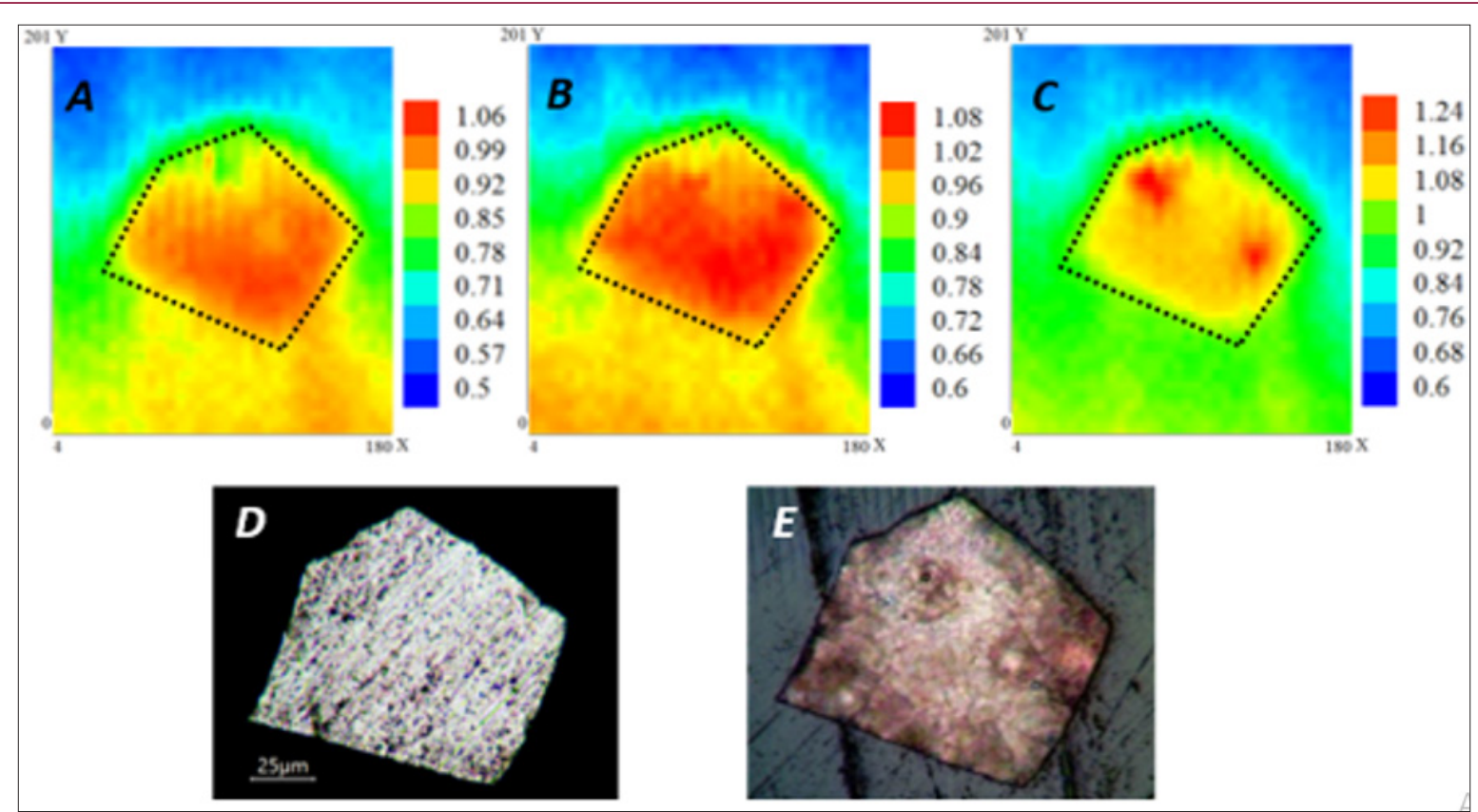

Figure 4: SECM maps of AZ31 in SBF + 2 mM FcMeOH recorded over a $180 \mu \mathrm{m} \times 200 \mu \mathrm{m}$ area (A) after 10 minutes, (B) 1 hour, and (C) 2 hours. Color scales are in nA. Dotted outline on SECM image indicates metal-insulator border of the substrate. Optical images of AZ31 (D) before, and (E) at the end of the experiment.

Figure 5 presents SEM images of the bare AZ31 surface (A) and after 2 hours of its exposure to SBF (B). The matrix (Figure 5-site 1) presents the basic alloying elements, corresponding to AZ31 (Figure 6 site 1). It can be observed that on AZ31 surface there are particles (in white color) (Figure 5A site 2), which EDS analysis (Figure 6-site 2) indicates that their composition could be attributed to the intermetallic Al-Mn secondary phase [29-33]. It is considered that these particles have less negative corrosion potentials than the Mg-matrix ( -1.52 to $-1.25 \mathrm{~V}$ vs SCE), so they could act as local cathodes, according to study of several magnesium alloys in 5\% $\mathrm{NaCl}$ solution [34-37]. Thereby, pit nucleation could take place around areas where Mg-matrix is in contact with those 
locally distributed cathodes on the AZ31 surface. It could be also seen that the formed corrosion layer is cracked (Figure 5B). The SEM observed pits nucleation correlate well with the localized surface activity detected in the map of SECM (Figure 4C) after the exposure in SBF.

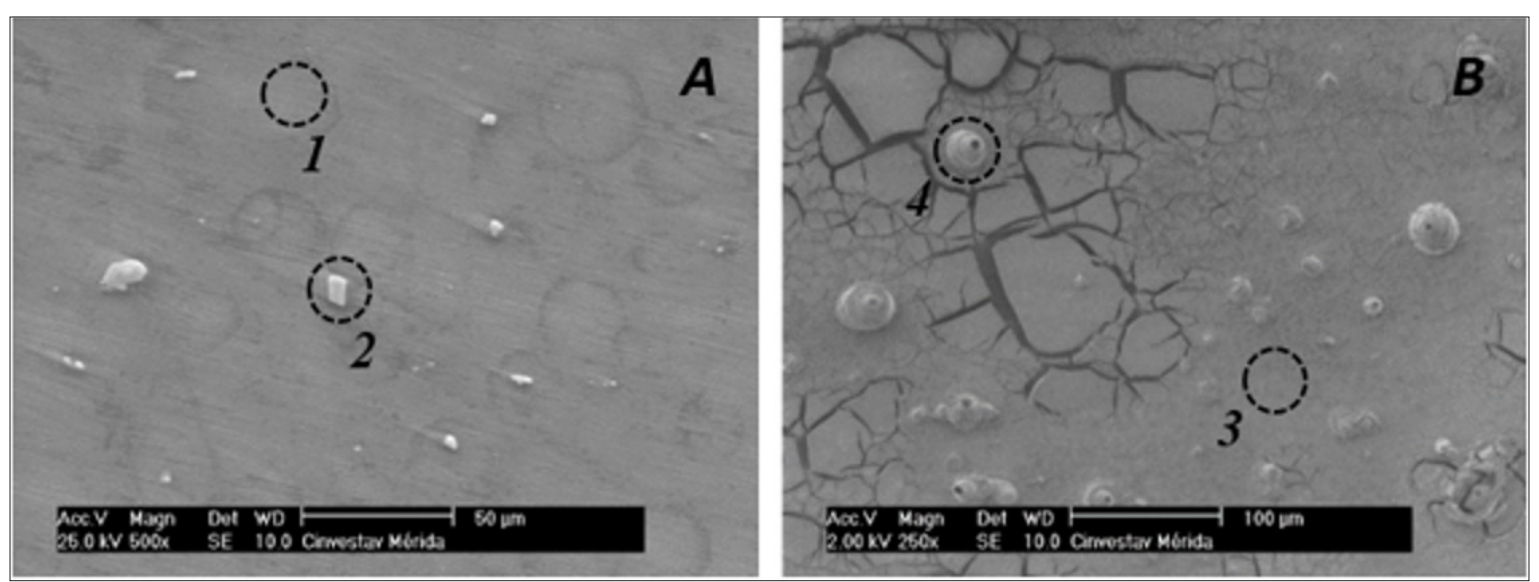

Figure 5: SEM images of AZ31 surface: (A) before and (B) after its exposure to SBF for 2 hours.

EDS analysis (Figure 6-site 3) of the corrosion layer of site 3 (Figure 5B-site 3) indicates that it contains C, O, P and Ca elements coming from the SBF solution, besides the basic elements of the alloy (Mg, Al, Zn). The pits (Figure 5-site 4) present Mn as an additional element (Figure 5-site 4), as a part of the local cathodes of Al-Mn, where the localized corrosion takes place. The main reported corrosion products for AZ31 in SBF are $\mathrm{Mg}(\mathrm{OH})_{2}$ and $\mathrm{Ca}_{10}\left(\mathrm{PO}_{4}\right) 6(\mathrm{OH})_{2}[38-42]$.

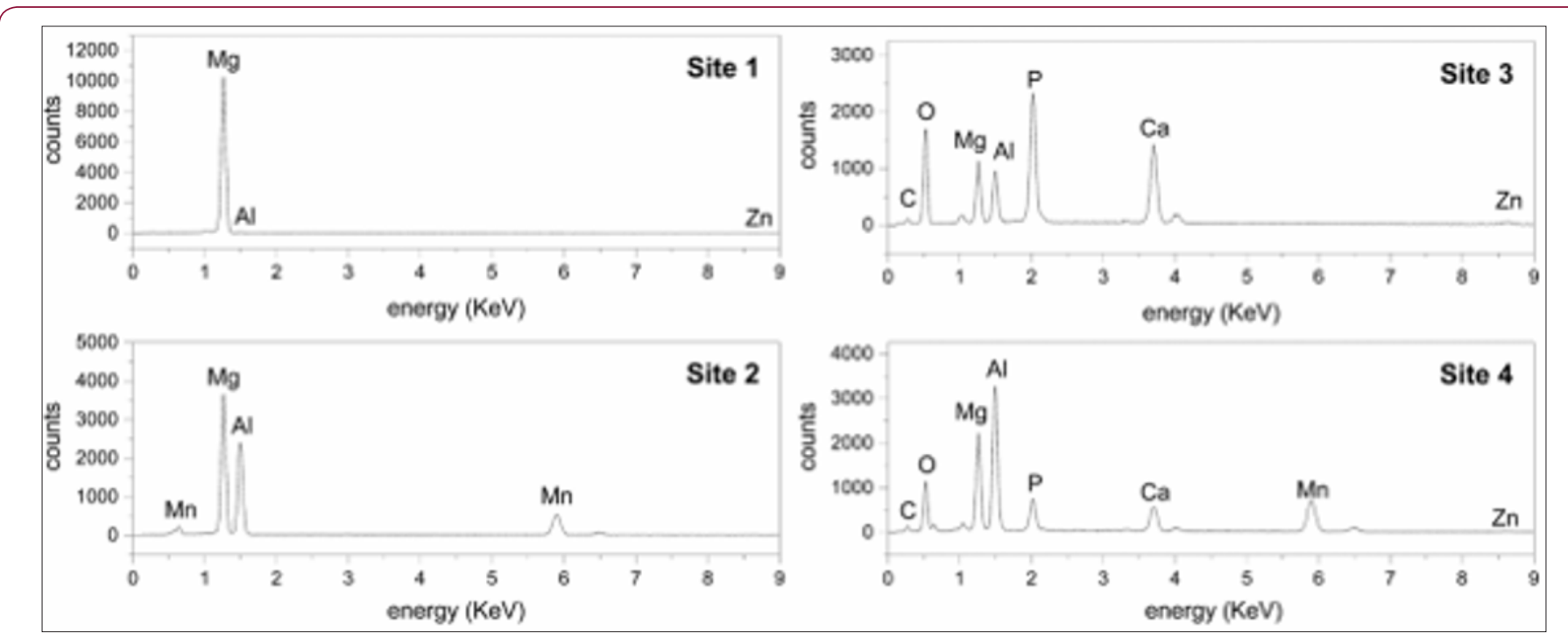

Figure 6: EDS elemental analysis of sites marked in SEM images (Figure 5).

\section{Conclusion}

Correlating SECM and SEM-EDS obtained results, it can be suggested that the initial behavior of AZ31 magnesium alloy exposed to buffered simulated body fluid (SBF) is as follows:

a) Since the very first moments of immersion, the alloy surface undergoes intense electrochemical activity related to a fast degradation and formation of a corrosion layer.

b) Such layer is susceptible to chloride ions penetration which accelerates the localized corrosion.

c) The pits nucleation is promoted by the presence of microgalvanic pairs of Al-Mn cathodic particles and the anodes of the Mg alloy matrix.

\section{References}

1. Witte $F$ (2005) In vivo corrosion of four magnesium alloys and the associated bone response. Biomaterials 26(17): 3557-3563.

2. Staiger MP (2006) Magnesium and its alloys as orthopedic biomaterials: a review. Biomaterials 27(9): 1728-1734.

3. Razavi M, Fathi MH, Meratian M (2010) Microstructure, mechanical properties and bio-corrosion evaluation of biodegradable AZ91-FA nanocomposites for biomedical applications. Materials Science and Engineering: A 527(26): 6938-6944.

4. Feng A, Han Y (2010) The microstructure, mechanical and corrosion properties of calcium polyphosphate reinforced ZK60A magnesium alloy composites. Journal of Alloys and Compounds 504(2): 585-593.

5. Seal CK, Vince K, Hodgson MA (2009) Biodegradable surgical implants based on magnesium alloys-A review of current research. IOP Conference Series: Materials Science and Engineering 4: 012011.

Cite this article: Emmanuel Mena M, Lucien V, David O W. Initial Electrochemical Activity of Magnesium Alloy AZ31 Surface Exposed to Simulated Body Fluid by Scanning Electrochemical Microscopy. Biomed J Sci \& Tech Res 13(2)-2019. BJSTR. MS.ID.002374. DOI: 10.26717/ 
6. Poinern GEJ, Brundavanam S, Fawcett D (2012) Biomedical magnesium alloys: a review of material properties, surface modifications and potential as a biodegradable orthopaedic implant. American Journal of Biomedical Engineering 2(6): 218-240.

7. Li Z (2008) The development of binary Mg-Ca alloys for use as biodegradable materials within bone. Biomaterials 29(10): 1329-1344.

8. Williams D (2006) New interests in magnesium. Medical device technology. 17(3): 9-10.

9. Xu L (2007) In vivo corrosion behavior of Mg-Mn-Zn alloy for bone implant application. Journal of Biomedical Materials Research Part A 83(3): 703-711.

10. Zreiqat H (2002) Mechanisms of magnesium-stimulated adhesion of osteoblastic cells to commonly used orthopaedic implants. Journal of biomedical materials research 62(2): 175-184.

11. Feyerabend F (2012) Ion release from magnesium materials in physiological solutions under different oxygen tensions. Journal of Materials Science: Materials in Medicine 23(1): 9-24.

12. Kirkland NT, Birbilis N, Staiger MP (2012) Assessing the corrosion of biodegradable magnesium implants: a critical review of current methodologies and their limitations. Acta biomaterialia 8(3): 925-936.

13. Mueller WD, Nascimento ML, De Mele MFL (2010) Critical discussion of the results from different corrosion studies of Mg and Mg alloys for biomaterial applications. Acta biomaterialia 6(5): 1749-1755.

14. Wipf DO (1994) Initiation and study of localized corrosion by scanning electrochemical microscopy. Colloids and Surfaces A: Physicochemical and Engineering Aspects 93: 251-261.

15. Tefashe UM (2014) Local flux of hydrogen from magnesium alloy corrosion investigated by scanning electrochemical microscopy. Journal of Electroanalytical Chemistry 720: 121-127.

16. Liu W (2014) Localized corrosion of magnesium alloys in $\mathrm{NaCl}$ solutions explored by scanning electrochemical microscopy in feedback mode. Electrochimica Acta 132: 377-388.

17. Jamali SS (2015) Evaluating the corrosion behaviour of Magnesium alloy in simulated biological fluid by using SECM to detect hydrogen evolution. Electrochimica Acta 152: 294-301.

18. Jamali SS (2014) Applications of scanning electrochemical microscopy (SECM) for local characterization of AZ31 surface during corrosion in a buffered media. Corrosion science 86: 93-100.

19. Izquierdo J (2016) Imaging of Concentration Distributions and Hydrogen Evolution on Corroding Magnesium Exposed to Aqueous Environments Using Scanning Electrochemical Microscopy. Electroanalysis 28(10): 2354-2366.

20. Dauphin Ducharme P (2015) Corrosion Product Formation Monitored Using the Feedback Mode of Scanning Electrochemical Microscopy with Carbon Microelectrodes. Journal of The Electrochemical Society 162(12): C677-C683.

21. Dauphin Ducharme P (2014) Local Hydrogen Fluxes Correlated to Microstructural Features of a Corroding Sand Cast AM50 Magnesium Alloy. Journal of The Electrochemical Society 161(12): C557-C564.

22. Asmussen RM (2015) Reducing the corrosion rate of magnesium alloys using ethylene glycol for advanced electrochemical imaging. Corrosion Science 93: 70-79.

23. Liu X (2009) Effect of alternating voltage treatment on the corrosion resistance of pure magnesium. Corrosion Science 51(8): 1772-1779.

24. Thomas S (2014) Possibilities and limitations of scanning electrochemical microscopy of Mg and Mg alloys. Corrosion 71(2): 171183.
25. Oyane A (2003) Preparation and assessment of revised simulated body fluids. Journal of Biomedical Materials Research Part A 65(2): 188-195.

26. Alpuche Aviles MA, Wipf DO (2001) Impedance feedback control for scanning electrochemical microscopy. Analytical chemistry $73(20)$ : 4873-4881.

27. Fan FRF, Demaille C (2001) The preparation of tips for scanning electrochemical microscopy, in Scanning Electrochemical Microscopy. (Eds.) New York, USA, p. 75-78.

28. Smith TJ, Stevenson KJ (2006) Reference electrodes, in Handbook of electrochemistry (Eds.). Elsevier: Amsterdam p. 92-93.

29. Cao P, StJohn DH, Qian M (2005) The effect of manganese on the grain size of commercial AZ31 alloy. In Materials science forum Trans Tech Publ pp. 139-142.

30. Wei LY (2000) Characterisation of Manganese-Containing Intermetallic Particles and Corrosion Behaviour of Die Cast Mg-Al-Based Alloys. Magnesium Technology 2000: 153-160.

31. Feng L (2010) Corrosion behavior of AZ31 magnesium alloy in simulated acid rain solution. Transactions of Nonferrous Metals Society of China 20: s638-s642.

32. Cheng Yl (2009) Comparison of corrosion behaviors of AZ31, AZ91, AM60 and ZK60 magnesium alloys. Transactions of Nonferrous Metals Society of China 19(3): 517-524.

33. Pawar S (2015) The role of intermetallics on the corrosion initiation of twin roll cast AZ31 Mg alloy. Journal of The Electrochemical Society 162(9): C442-C448.

34. Lunder O, Nisancioglu K, Hansen RS (1993) Corrosion of die cast magnesium-aluminum alloys. SAE Technical Paper.

35. Song G, Atrens A (2003) Understanding magnesium corrosion-a framework for improved alloy performance. Advanced engineering materials 5(12): 837-858.

36. Song G, Atrens A, Dargusch M (1998) Influence of microstructure on the corrosion of diecast AZ91D. Corrosion science 41(2): 249-273.

37. Lafront AM, et al. (2005) Pitting corrosion of AZ91D and AJ62x magnesium alloys in alkaline chloride medium using electrochemical techniques. Electrochimica Acta 51(3): 489-501.

38. Xin Y (2009) Corrosion products on biomedical magnesium alloy soaked in simulated body fluids. Journal of materials research 24(8): 27112719.

39. Xin Y, Hu T, Chu PK (2011) Degradation behaviour of pure magnesium in simulated body fluids with different concentrations of HCO3. Corrosion Science 53(4): 1522-1528.

40. Song Y, et al. (2009) Biodegradable behaviors of AZ31 magnesium alloy in simulated body fluid. Materials Science and Engineering: C 29(3): 1039-1045.

41. Van Phuong N, Gupta M, Sungmo M (2017) Enhanced corrosion performance of magnesium phosphate conversion coating on AZ31 magnesium alloy. Transactions of Nonferrous Metals Society of China 27(5): 1087-1095.

42. Mena Morcillo, Veleva E LP, Wipf DO (2018) Multi-scale monitoring the first stages of electrochemical behavior of AZ31B magnesium alloy in simulated body fluid. Journal of The Electrochemical Society 165(11): C749-C755. 


\section{ISSN: 2574-1241}

DOI: 10.26717/BJSTR.2019.13.002374

Lucien Veleva. Biomed J Sci \& Tech Res

CC (i) This work is licensed under Creative

Submission Link: https://biomedres.us/submit-manuscript.php

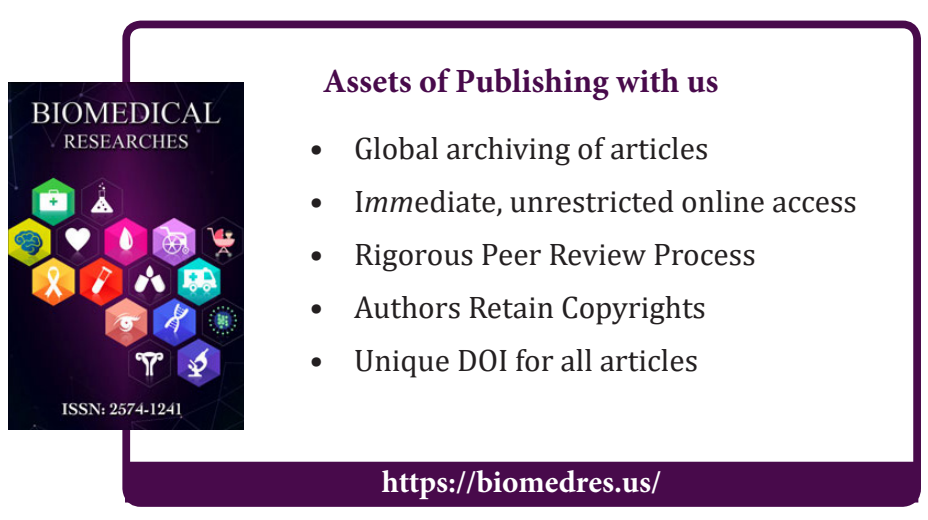

